\title{
Erratum to: Numerical investigation of MHD water-based nanofluids flow in porous medium caused by shrinking permeable sheet
}

\author{
P. Valipour ${ }^{1}$ S. E. Ghasemi ${ }^{2}$
}

Published online: 25 July 2016

(C) The Brazilian Society of Mechanical Sciences and Engineering 2016

Erratum to: J Braz. Soc. Mech. Sci. Eng. (2016)

\section{8:859-868}

DOI 10.1007/s40430-014-0303-3

The original version of this article unfortunately contained a mistake.

The affiliation of the second author was incorrect. The correct information is given below.

S. E. Ghasemi, Young Researchers and Elite Club, Sari Branch, Islamic Azad University, Sari, Iran

The online version of the original article can be found under doi:10.1007/s40430-014-0303-3.

S. E. Ghasemi

s.ebrahim.ghasemi@gmail.com

1 Department of Textile and Apparel, Qaemshahr Branch, Islamic Azad University, Qaemshahr, Iran

2 Young Researchers and Elite Club, Sari Branch, Islamic Azad University, Sari, Iran 